\title{
Adsorption of Humic Substances by using Coconut Copra
}

\author{
M.F.Atan ${ }^{1, a}$, K.A.Mapi ${ }^{1}$, S.N.F.Ghazali ${ }^{1}$, N.Abdul Rahman ${ }^{1, b}$ and \\ S.F.Salleh ${ }^{1, \mathrm{c}}$.
}

${ }^{1}$ Department of Chemical Engineering and Energy Sustainability, Faculty of Engineering, Universiti Malaysia Sarawak, 94300 Kota Samarahan, Sarawak, MALAYSIA

aamfarid@feng.unimas.my, barnazeri@feng.unimas.my, csshanti@feng.unimas.my

Keywords: Adsorption, Humic Substances, Batch Stirred Tank Reactor, Coconut Copra.

Abstract. Nowadays, consumers are concern about the quality of water that being supplied in order to ensure the water supplied is free from any harmful substances for example like Humic Substances (HS). High concentration of HS in drinking water can cause disease for human such as stomach cancer. Thus, it is important to develop a new technique to improve the quality of drinking water. Therefore, the objective of this research is to investigate the potential of using coconut copra treated with citric acid as activated carbon in adsorbing HS contained in wastewater collected from Asajaya Treatment Plant situated in district of Samarahan, Sarawak. In this research, the optimum condition of adsorption process need to determined. As such, there are two types of parameters which are considered as constant; temperature and $\mathrm{pH}$ of activated carbon and variable; solid liquid ratio and residence time. As a result, this research has shown that coconut copra possess the capacity to adsorp $97.5 \%$ of HS contained in wastewater.

\section{Introduction}

Environmental pollution has extremely increased in Malaysia especially in water pollution. Water is one of the important needs of human on this earth. Consumers nowadays stress on the quality of water which is supplied to them in order to ensure that the water supplied is free from any harmful substances for example Humic Substances (HS). HS are the most widely distributed products from biosynthesis that contained in soil. Apart from soil, it also can be found at different level of concentrations in different sources like rivers, lakes, oceans, compost, sediments, peat bogs and soft coal. HS are formed by a process called humicification [1]. HS are divided into three main fractions which are Humic Acid, Fulvic Acid, and Humin. It can be classified based on solubility in acids and alkaline [2]. High concentration of Humic Acid in drinking water can cause some serious diseases on human health for example stomach cancer which is due to the disinfection caused by by-products namely trihalomethanes [3, 4, 5]. Humic Acid contains relatively high amount of basic Amino; combination of functional groups of Amine and Carboxylic Acid, becomes poisonous if the molecular weight of Amines is relatively low [6,7]. On the other hand, Amines are not totally harmful but when it reacts with the other compounds, it will form nitrosamines and nitramines which have an irreversible effect on environment, human and animals. Some of the amino compounds have also been known or suspected carcinogens due to the aromatic amine which can cause disease like bladder infection [8]. Therefore, it is important to remove HS especially Humic Acid from drinking water. As mentioned by Hatam et al, high amount of Humic Acid can become one of the etiological factors for Blackfoot disease [6]. Therefore, the objective of this research is to investigate the potential of using coconut copra as activated carbon in adsorbing humic substances contained in wastewater collected from local wastewater treatment plant namely Asajaya Treatment Plant located in district of Samarahan. 